\title{
Modeling Musical Capabilities - Guitar Playing
}

\author{
Dan Florin Stanescu, PhD, Associate Prof. \\ National University of Political Studies and Public Administration \\ Bucharest, Romania
}

doi: 10.19044/esj.2016.v12n11p54 URL:http://dx.doi.org/10.19044/esj.2016.v12n11p54

\begin{abstract}
While it is possible for one to detect a person's dexterity upon an instrument visually, auditorily and sometimes even kinaesthetically, it is the hypothesis here that there are other sets of skills which are just as important to musical capability as the manual technique applied when playing the instrument. Modeling is a process whereby an observer gathers information about the activity of a system with the aim of constructing a generalised description (a model) of how that system works. The purpose of this study is to identify strategies and patterns in how musicians organized their experience of the world around them and then acted in that world so that we may gain some new insights on how they operate. In order to get relevant data, direct observation and interview were employed. For this purpose three exemplar were selected. With each of them an in-depth interview was conducted (videotaped). All the components of the schema were elicited, using an interview schedule (Darlington \& Scott, 2002, 141), which followed Dilts logical level model (Dilts, 1998). At the end of the interview each exemplar was asked to perform a piece of music for a live observation of exemplar achieving their results (Frost, 2011).
\end{abstract}

Keywords: Modeling, guitar playing, musical capabilities, logical levels

\section{Introduction}

The term modeling has latin roots from the word modus, which has different meaning such as: a manner of doing or being; a method, form, fashion, custom, way, or style (www.latinwordlist.com). Webster's Dictionary defines a model as "a simplified description of a complex entity or process" - such as a "computer model" of the circulatory and respiratory systems (www.merriam-webster.com).

The notion of a "model" has also come to mean "a description or analogy used to help visualize something (as an atom) that cannot be directly observed" (Dilts, 1998, 28).

Behavior modeling, such as musical capabilities, involves observing 
and mapping the successful processes which underlie performance in a specific field of activity. The aim underlying behavior modeling is to create a 'model' of that behavior, a pragmatic one, which can be used to reproduce or simulate some aspect of that performance. The goal of the behavior modeling process is to identify the essential elements of thought and action required to produce a specific outcome. As opposed to providing purely correlative or statistical data, a 'model' of a particular behavior must provide a description of what is necessary to actually achieve a similar result (Dilts, 1998, 29).

But in order to develop an effective model of a particular behavior or performance, one need to involve more than simply observation and imitation. In modeling an individual there are a number of different aspects, or levels, of the various systems and sub-systems in which that person operates that we may need to explore.

At one level, for instance, one can look at the social and contextual environment influences on a person - i.e., in our case, when and where the person is acting or performing. At the same time, one can examine also the influence and impact that the individual may have on the environment.

At another level, following the Dilts model (1998), one can examine the specific behaviors and actions that a person engages in while performing a specific activity- i.e., what specifically the person does within the environment. One may also look at the intellectual and cognitive strategies and capabilities, which are required for the actions within the identified environment - i.e., how a person generates the behaviors in that context. One could further explore the beliefs and values that motivate and shape the thinking strategies and capabilities that are required to accomplish the behavioral goals in the environment - i.e., why a person does things in a particular time and place. One could look even more deeply to investigate the perception of role or identity a person has in relation to his or her beliefs, capabilities and actions within a particular environment - i.e., the who behind the why, how, what, where and when. This would involve potential issues relating to role definition, character traits, personality, etc. A key element in establishing a particular role or identity involves defining the sense of mission a person has within the larger system in which he or she is operating. One might also want to examine the way in which a particular person operates within the relational context of family, colleagues, social class or culture - i.e., who the person is or will be in relation to who and what else. In other words, what is the vision of the individual with respect to the purpose of their behaviors, abilities, beliefs, values and identity within the larger systems of which he or she is a part? It is often this vision, which gives all of the other levels their ultimate meaning (Dilts, 1998, 34-36).

The final objective of any modeling process is not to end up with a receipt or the right description of a person thinking and behavioural process, 
but rather to create an instrumental map which can allow one to apply the extracted strategies in a useful way. Thus, the instrumental application of the behaviors or cognitive strategies modeled from a particular individual or group of individuals involves putting them into structures that allow us to use them for some practical purpose such as guitar playing.

The focus of most modeling processes is at the level of capabilities, the how to level. Capabilities connect beliefs and values to specific behaviors (Dilts, 1998). Without the how, knowing what one is supposed to do, and even why to do it, is largely ineffective. Capabilities and skills provide the links and leverage to manifest our identity, values and beliefs as actions in a particular environment.

\section{Methods}

One of the most important parts of any modeling process is the methodology used to gather information and identify relevant features and patterns employed by the selected models. In order to to obtain the relevant date for the current research two methods were employed - observation and interview. Both methods allow "first hand" information gathering. The observation is very useful for understanding of the context of the respective behaviour and facilitates the identification of relevant questions that are going to be used in the interview (Ritchie \& Lewis , 2003 ,76). To avoid any loss in information (both in terms of the qualitative and quantitative analysis) we chose video recording of both observation and interview sessions, as recommend by Ritchie and Lewis (2003 , 79).

The interviews were organized as face to face meetings, and were video recorded (after the consent) in order to facilitate the detailed analyze of some relevant aspects encountered in modeling process (Milton meta model, sensory predicates, filters etc.). To identify the specific sensory predicates and other semantic aspects, the version 8.1 of Tropes semantic analysis program was used. All three interviews were then transcribed into word files and further analized using the interpretative phenomenological analysis (IPA) methodology (Smith, Flowers, \& Larkin, 2009). IPA combines a dedication to understanding the lived experience of the participant and provides a systematic approach to conducting qualitative research (Smith \& Osborn, 2003) that is committed to idiographic inquiry (Lamiell, 1987; Smith et al., 1995). Each case is examined in great detail as an entity before moving to a more general claims which are translated into a narrative account that includes detailed extracts from the participants' accounts.

IPA it is concerned with the meaning of such experinces for those participants (Larkin, Watts \& Clifton, 2006). IPA is particularly useful where the topic under study is multidimensional, dynamic, contextual and subjective, relatively novel and where issues relating to identity, the self and 
sense-making are important (Smith, 2004). Each interview lasted between an hour and an hour and a half. Verbatim transcripts of the semi-structured interviews served as the raw data for the study.

In addition to questionnaires and interviews, it is often useful and necessary to incorporate more active methods for gathering information such as role plays, simulations, and the 'real life' observation of the expert/model in context. In this respect we also had the opportunity to observe "at work" (participatory observation) two of the models - Edward and Gabriel.

Regarding the semi-structured interview, it was selected due to the fact that it is a form which combines flexibility with structure (Darlington \& Scott 2002, 141). The questions in the interview are usually open in order to encourage participants to speak more. Also, questions should not contain any assumptions about participants' experience or lead to a certain specific response (Frost, 2011).

\section{Interview guide}

The interview guide is a list of questions or issues to be explored in the interview. In this framework the interviewed person has the freedom to spontaneously talk about certain topics and to establish their own conversational style (Patton, 2002, 343). Starting from the idea that the way people perceive life experience will be directly reflected in how they talk and behave vis-a-vis this experience (Dean, Smith \& Payne, 2006), in this project we developed and used (mostly) the following interview guide:

- Tell me please about ....

- Describe me please how the environment needs to be around you when you study or play the guitar.

- What do you do concretely? How do you know what to do? How do you know you do well (or not) what you do?

- What skills do you need to be able to do that? How do you know they are needed? Have you also need something else?

- What beliefs, about yourself, music etc. helped you (or not) to reach the level where you are now?

- Who are you the one who plays guitar? What can you tell me about yourself?

- Who else is influenced by what you do / you are able to do?

-What can you tell me about body position, instrument, hands etc.?

- Describe me the experience of playing the guitar, or studying. What do you do exactly?

- What is the internal state that makes you play / study?

- How do you feel? How do you feel? Where? Describe the feeling.

-What are you thoughts when you practice / plaiyng for pleasure? 
- What is the difference between a good "piece" and one less successful?

- What advice would you give to someone who wants to learn to play the guitar?

- Please play something that you enjoy. Now a song that is more difficult.

- If you think something should be added ...

As it was mentioned before, the data were analyzed using interpretative phenomenological analysis (IPA). The analysis followed very closely the four-stage process described in detail in Smith and Osborn (2003). Analysis began with a close interpretative reading of the first case where initial responses to the text were annotated in one margin. These initial notes were translated into emergent themes at one higher level of abstraction and recorded in the other margin (Osborn \& Smith, 2008). The researchers then interrogated the themes to make connections between them. This resulted in a table of super-ordinate themes for the first case within which were nested the subordinate themes with identifying information, that is, where the instances supporting the theme can be found within the interview transcript. This process was repeated for each case. After the analysis had been conducted on each case, patterns were established crosscase and documented in a master table of themes for the group. This was then transformed into a narrative account; the analytic account was supported by verbatim extracts from each participant.

\section{My models ${ }^{1}$ - short description}

While it is possible for one to detect a person's dexterity upon an instrument visually, auditorily and sometimes even kinaesthetically, it is the hypothesis here that there are other sets of skills which are just as important and just as essential to musical capability as the manual technique applied when playing the instrument. The models that we have chosen are not musicians in the true sense (earning their living from music); they are musicians in the sense that they are able to demonstrate that they understand the music, they can play the guitar at an acceptable level for public representation and can explain to others how they proceed in this regard.

Gabriel - 44 years old man who and began playing guitar since childhood. My contact with him (as a performer and composer) is very long, beeng able to appreciate both his evolution and migration to classical guitar. Since 2003 the focus was mainly on classical guitar. Currently he is seldom studying and plays the guitar only for pleasure in small personal gatherings.

\footnotetext{
${ }^{1}$ Due to confidentiality the participants real names were changed
} 
Matthew - Matthew is 34 years old man and plays guitar only for pleasure. He studied guitar for 2 years at the Art School (more than 10 years ago) and occasionally studied with a former guitar teacher neighbor. He had contact with music since childhood when he studied violin for several years. Currently Matthew plays only in restrained framework (family, friends, Christmas etc.).

Edward - Edward grew up in a family where music was always present, his mother being a violin teacher. Obviously, he studied violin for seven years and after he then began to study classical guitar at the National Military Circle. He studied classical guitar for three years, during this period discovering the passion for rock music, especially heavy metal. He begun to compose heavy metal songs since high school. Currently he is palying for pleasure, with friends or when he has new compositions ideas.

One aspect discovered looking retrospectively at the selected models is that they are all intelligent and gifted people (two of them having PhD) with a highly reflexive capacity, able to explore and verbalize a wide range of feelings, emotions, specific thoughts and behaviors.

\section{Results}

After finalizing the interviews transcription we end up having a huge amount of information. The decision was made to present the data following the neurological levels model (Dilts, 1998) using the themes extracted from the IPA analysis.

The fist model interviewed was Gabriel. It was very rich experience, both in terms of the amount of information and the experience itself. One can easily notice the preponderance of kinesthetic and auditory predicates (42; heavy, going forward, break, feel, grasp, push, warm, helping hand, support, inertia; 19; sound, hear, listen, say). Regarding meta-programs (Bandler \& Grinder, 1975), the following patterns were identified: toward - resultsoriented, internal - motivation comes from within, from internal state, self inward orientation of thoughts and feelings. Analysis of transcripts following the neurological levels led to the following results:

Environment - ... I'd love a company, a support, to have someone next to you. (...) Certainly not many people, very few, one - maximum two ... (...) is completely isolated. It is not that I do not hear or see what happens, I see and hear but things goes by completely.

Behavior - right hand neither too high, nor too low to touch ... right, relaxed. The forearm rests on guitar. Guitar sits on the left foot, left hand is relaxed and cam move as a trolley on the fingerboard, with the back thumb supporting different accords in a natural way. The elbow never stays stuck to the body, it has to be perpendicular to the fingerboard. (...) A lot of frustrating exercise... First a lot of exercise. Secondly listening a lot of music 
performed by masters of the instrument. (...) I play the guitar in different moments ... when I have nothing to do, or when I am with many people and I feel I do not know what to say or at that moment I have nothing to say ...

Skills - I think, first of all rhythm. Musical ear ... And then some physical skills that, in my opinion you are born with. For example hands and fingers independence... (...) A lot of perseverance and patience. Patience. Patience, a lot of patiente especially in the beginning (...) The desire to do it.

Beliefs - I think, to be honest... is that narcissistic component that gives you satisfaction when you manage to do something that not many others are able to. And when you present yourself doing something special it gives you something in addition... (...) you know, a kind of personal satisfaction so ... you feel and you can ... be more important than others ... you feel a little out of the crowd... and this gives you something extra ... (...) It goes along with me. When I work, when I am doing anything, I whistle, the music is playing in my head. It goes along like a kind of device... like listening to a radio, just that I am the radio, myself. (...) It's like an open field for a horse. He has that space in which he can run. (...) ... It's like you weigh a little less than normal, as if you were a little lighter ...

Identity - An Artist. A sensitive person who is aware of ... but I think it's the same with what I am normally. A person aware of what surrounds him.

Spiritual - My family. Well I think all of them. In a positive way because they enjoy, they enjoy listening. Perhaps they enjoy also the fact that I am amble to to do something rather special that not everibody is able to.

The second model interviewed was Matthew. After the interview transcription, the analysis showed that he mainly used auditory predicates (39; resonates, say, sound (like), listen), followed by kinesthetic ones (28; feel, flowing, fluent, get stuck, light, relaxed, touch, broken). The main set of patterns were internal - motivation comes from the inside, deductive indepth, in detail, self - concerned about own thoughts, emotions, similarity recognizing similarities. In terms of neurological levels the transcript analisys lead to the following findings:

Environment - ... most often it is a matter of isolation. ( ... ) I believe though, that in most contexts, it's about isolation.

Behavior - I can not say it is a ritual, but first, I check the tuning and then began to play. ( ... ) Sometimes, I do some comments using inner voice. It sounded well, this one not so well... ( ... ) ... Usually I grasp the guitar when I am in a certain mood. When I am little blue, or I am sick of doing something, to write a report for instance. Yes ... or when I have something in my head, a song and I want to see how I would sound like. So in this way ... But, the most frequent or dominant are those state related... a specific type of melancholy... 
Skills - First should have some musical competencies... clearly musical ear, a certain sense of rithm. (...) I think that there is something else, something related with one's artistic or poetic side. I mean, a certain competence for expression or to express something. (...) ... It is clear that it takes perseverance. So that's clear, perseverance, tenacity. (...) I mean, if someone wants to learn, he or she has to take things seriously, first to establish a kind of repertoire, of he/she wants to sing, to make a systematic program, to talk to a teacher. And to maintain the peace. (...) Perseverance. That's it! Then, to have a good look to the artists in the musical area in which he/she wants to perform. And then to see the differences in the approach of a specific song. I mean to steal from masters. To look carefully, to listen, to create a musical culture of that area. Beliefs - .. it's a very personal thing this playing (...) For me, music and sexuality are the only non-semantically forms of self construction. Yes, it's a way to take you by surprise. I believe this is an essential thing in relation with music. To be able to take you by surprise.

Identity - And, it is like a form of expression... it's something overflowing and needs to get out somehow. (...) When I'm playing the guitar I am... a man who works with himself. To see what comes out, to see if you can make it, to see how flexible you are. To see if the dough has also something to say about it.

Spiritual - For me, this dimension of public playing does not exist; I believe that this would create high degree of inhibition for me. Also for my colleagues it was relevant for a while the fact that I know to play the guitar. But I believe that mainly for my relation with myself. The rest, I could live without, no problem.

Edward was my last interviewed model. It made me a great pleasure to run this interview and to have access to such rich information. Analysis of Edward's transcript showed that he use mainly kinesthetic predicates (46; feel, do, get in touch, fully aligned, strength, power, step, break, comes, runs, support, placing, effervescence, go, keep, start, put your hand), followed by auditory predicates (39; say, listen, resonance, stuttering, jingle, acute), similarly with both Gabriel and Matthew. Regarding meta-programs, the following patterns were identified: toward - results-oriented, internal motivation comes from the inside, self - concerned about own thoughts, emotions, future oriented - planning specific activities and its vision.

The analisys of Edward's transcript lead to the following findings in terms of neurological levels:

Environment - I do not sepparate myself in any way from the world, but I really appreciate if someone does not interrupt me.

Behavior - the experience of guitar playing puts your mind in motion on a kind of intellectual activity with aesthetic notes. (...) It is a special 
experience, this is the word. If you can have this experience you must have it. When you play the guitar, and your mind is focused on what you do, you have the feeling of satisfaction or even of personal accomplishment. (...) Each song is like a 'food', but as a source that feeds you spiritually.

Skills - ... a person with a normal psihosomatic development; perhaps some are more gifted than others regarding musical skills but everything is work. But in all this thing, in my opinion, what matters most is the character. (...) The will and desire, the call, the call to sing. You cannot live without this.

Beliefs - for me music is the most noble activity possible. I believe that is an activity that ennobles you. That's the word, in a purely private sense of course, intrinsically. I mean you feel more pure.

Identity - Edward is the one singing with himself. And perhaps this is the only activity in which I am one with myself, how to say ... do pure but complete. ... it's about the feeling of accomplishment.

Spiritual - I am with myself. I would have liked those around me to understand.

\section{Conclusion}

After interviewing the three models, I have realized that although many of the things I have discovered are similar, they are not the same. I've noticed also that each of them has its own particular map of the world. I believe that in this kind of endeavour it is important to understand that what may function quite well for them may not work as well in my case. Therefore, after careful examination of the gathered information, we have created a model that might be followed, a model in which we have integrated different parts of my models elicitated strategies. Coming back to the Dilts (1998) neurological level, the final model looks as follow:

Environment - assure that there will be no interruptions during lessons; not so many people around;

Behavior - be patient; be perseverant; studying with a teacher; establish clear objectives; listening to the masters;

Skills - musical ear and sense of rhythm; open to artistic/esthetic experiences; good arms/fingers independence;

Beliefs - I have all the necessary resources; there is no failure, only feedback; I believe that we all have the capacity to learn; if others managed to learn I am also able to do it; music ennobles you;

Identity - I am a sensitive person who is able to express his inner world trough music;

Spiritual - I might influence others to start playing (especially my kids); I can bring joy to people around me. 
During the modeling process, especially during the interview sessions, I was really privileged to discover three wonderful people, willing to open in such a way, to explore and share how they do what they do. I want to thank my models, Gabriel, Matthew and Edward for their time, for their willingness to participate in the study (and by accepting to videotape the interviews) and for the diponibility to explore, together with me, their own strategies, beliefs and behaviors.

\section{References:}

Darlington, Y. \& Scott, D. (2002). Qualitative research in practice. Stories from the field. Crows Nest: Allen \& Unwin.

Dean, S.G., Smith, J.A. \& Payne, S., (2006). Low back pain: Exploring the meaning of exercise management through interpretative phenomenological analysis, in Finlay L. \& Ballinger, C., Qualitative Research for Allied Health Professionals: challenging choices. London: John Wiley \& Sons.

Dilts, R. (1998). Modeling with NLP. California: Meta Publications.

Frost, N. (2011). Qualitative Research Methods in Psychology: Combining core approaches. Glasgow: Open University Press.

Lamiell, J. (1987). The psychology of personality. New York: Columbia University Press.

Larkin, M., Watts, S., \& Clifton, E. (2006). Giving voice and making sense in interpretative phenomenological analysis, Qualitative Research in Psychology, 3:2, 102-120.

Osborn, M., \& Smith, J.A. (2008). The Fearfulness of Chronic Pain and the Centrality of the Therapeutic Relationship in Containing It: An Interpretative Phenomenological Analysis. Qualitative Research in Psychology, 5, 276288.

Patton, M.Q. (2002). Qualitative research \& evaluation methods - 3 ed. California: SAGE Publications.

Ritchie, J. \& Lewis, J. (2003). Qualitative Research Practice. A Guide for Social Science Students and Researchers. London: SAGE Publications.

Smith, J. A. (2004). Reflecting on the development of interpretative phenomenological analysis and its contribution to qualitative research in psychology. Qualitative Research in Psychology, 1, 39-54.

Smith, J. A., Harre, R., \& Van Langenhove, L. (1995). Idiography. In J. A. Smith, R. Harre \& L. Van Langenhove (Eds), Rethinking psychology. London: Sage.

Smith, J.A., Flowers, P., Larkin, M. (2009). Interpretative pheomenological analysis: theory, method and research. London: SAGE Publications.

Smith, J. A., \& Osborn, M. (2003). Interpretative phenomenological analysis. In J. A. Smit (Ed.), Qualitative psychology: A practical guide to 
research methods (pp. 51-80). London: Sage.

www.latinwordlist.com, retrieved at 23.05.2015

http://www.merriam-webster.com, retrieved at 23.05.2015 